\title{
The Green Marketing Strategy in Selected Lubricant Sector in the Kingdom of Saudi Arabia and Its Implications to Corporate Organizational Growth
}

\author{
Hosam Azat Elsaman', Rommel Pilapil Sergio ${ }^{2}$ \\ ${ }^{1}$ York St. John University, United Kingdom \\ ${ }^{2}$ Abu Dhabi School of Management, United Arab Emirates
}

\begin{abstract}
Corporate social responsibility has faced critical issues for many modern organizations, it mainly pushes to continue the commitment of enterprise towards ethical and moral value in terms of economic development while improving the overall quality of the organization. The research aims to address as to what extent adopting corporate social responsibility policies would improve organisational performance, other than focusing on the link as to how applying green marketing strategies in the field of lubricant in KSA can maximise the profitability of the company. Furthermore, the paper analysed the consumer's perception of lubricant industry experts and end-users in KSA market toward the new green lubricants concept. The research methodology based on positivism philosophy with deductive approaches and descriptive design while the sampling techniques followed snowball and accessibility sampling frame with a total number of 176 respondents. Through quantitative method particularly through survey, the key findings of this research point to the supportive feedback from the consumer and industry experts in producing environmentally friendly products, and lastly, the discussion of the positive implications of green marketing strategies for the organization as the result of implementing CSR policies.
\end{abstract}

Keywords: Corporate social responsibility, value, ethics, moral values

\section{Introduction}

Nowadays the environmental subject, and how to save the nature consider an important goal for most of organisations in different industries. Many corporates adopt the sustainability and new organization which are environment friendly to apply green activities. These green activities are implemented in organization to ensure all the processes, products and manufacturing are based on the principle of environment safety. The theory of corporate social responsibilities (CSR) for the business means that for any company should not depend on economic and legal factors to gain profit but should go more than that by considering the social and ethical factors as well. Management style of corporate should coordinate between 
approaching more financial profits while improving people's lives and sustain the nature and the planet. Green marketing strategies consider a valuable tool to approach that target of applying CSR for the organization. Based on the definition of American Marketing Association for green marketing as the marketing of concepts or goods that are believed to be eco-friendly by modifying the promotions tactics to increase awareness of marketing new product with industries (Yazdanifard, 2011; Rajeshkumar, 2012). Moreover, it is defined as the promotion of ecological concept or meeting the demands of the present market without reducing the chances of the future generations to meet their own needs (Sergio, Refaat, \& De La Cruz, 2016; Rajeshkumar, 2012; Suki, 2013).

Green Marketing based on the phenomenon mainly developed in the modern marketplace. It enables the actual package item, which already complies with different guidelines. The concept of green marketing connects with the business opportunity for improving quality of green product. Many countries around the globe that have recently pursued sustainability. In terms of green marketing, the Government and the public are demanding because of sustainability in the global world. The environmental disaster caused by human-made activities and pollution which directly impact on the ecological system (Ahmed, Sultana and Khan, 2018).

Presently, it is a crucial subject to save nature by consideration of specific goals and objectives. The lubricant sector has been rapidly increasing in the international market while produce waste materials, generate emission of gases, at that time it has required for adopting sustainability which requires to create environment friendly practising. It is applying the green activities which are implemented in the organization. It must ensure that all products, processes, and manufacturing based on the principle of environment safety. It also implements the corporate social responsibilities theory, highlights the relationship between stakeholder and corporate while including the safety parameters related environment.

There are numerous amounts of natural resources are being consumed on regular basis, that increased the need for controlling and managing the consumption of innovative alternative options. It is potentially increasing to sustainable development and reduce environmental pollution. Increasing pollution rate has put significant pressure on the governments, corporates, and most of the industrial sector, particularly oil \& gas industry. Therefore, international efforts are working to promote for implementing the concept of Green Marketing in the lubricant industry (Krane, 2018; Suki, 2013). It helps to control the harmful emissions of carbon dioxide, as a result of operational activities in the organization smoothly. Many countries aware of the pollution while setting up a strict environment law because of climate change.

Saudi Arabia is the largest producer as well as exporter in lubricant item, which considered as the largest consumer of oil and lubricants in the Middle East by the capacity of $450 \mathrm{k}$ tons per annum. That is why it must face a distinctive problem with greenhouse emissions because of that vast quantity of lubricants consumptions. Therefore, it requires reducing the environmental footprint and enhancing sustainability. Once set up the Green lubricants technology, that will produce half of its power from the other renewable source by 2025 . 
Through Green marketing strategy it can be achieved the specific goals and objectives of ecological targets (Ahmed, et al., 2018).

The primary aim of Green Marketing Strategy is to provide awareness among the organizations so that it will increase sustainability and reduce the price of operation, maintain wealth, and reduce pollution in the global environment. The step of identifying the barriers related environment due to the lubricant industry which continuously produce waste and emission. The barriers are different from one nation to another. Hence, economic, political, culture and economic factor can influence the severity and quantity of challenges.

The research focuses on the oil and gas industry. This paper investigates the oil lubricant industry and how to become a market pioneer in KSA by applying new green oil technology. Currently, the lubricant sector consists of upstream, midstream, and downstream. Saudi Arabia has a large number of oil-based firms which will increase its production of oil and supply in other countries. In this way, it will be generating the high pollution which directly impacts on the environment (Krane, 2018).

Many organizations related to lubricant field will implement the green marketing strategies that help to improve the overall performance within the global marketplace, by introducing the revolutionary new green technology that can be applied as the first time in the market of Saudi. Moreover, the study described the measurement which evaluates for identifying effects of launching eco-friendly green items for business to increase the productivity and profitability and consider social along with environmental factors (Ahmed, et al., 2018). As well as outline the feedback of lubricant industry experts and other end users in the Saudi market where how they can use the different green item for business expansion. Furthermore, it will review the effectiveness of applying CSR policies, which improves overall business performance.

\section{Research Objectives}

The paper has the following research objectives:

1. To ascertain how the corporate social responsibility policies improve organization performance as perceived by the respondents.

2. To identify the feedback of lubricants industry experts and end-user in Saudi Arabia market toward the green products use.

3. To apply the green marketing strategies that contribute to organizational growth. 


\section{Literature Review}

\subsection{The Green Marketing Strategies in Lubricant Industry}

Organization can apply green marketing to maximize profits. Plus, green marketing can achieve the equilibrium between save the environment and satisfying consumer's needs. Thus, green marketing considers reason to increase competitive advantage for the organization. Nowadays people have more awareness according to healthy lifestyle. Consequently, green marketing is not only an environmental factor tool but also a marketing strategy. Applying new eco-friendly concept will attract more consumers, the company will get more advantage when adopting and applying green marketing strategy (Yazdanifard, 2014).

To enhance the effective implementation of green marketing by using environmentally friendly tools like biodegradables labels, and ecological advertisement, should be involved as part of the green marketing methods. Meanwhile, due to applying the proper marketing campaigns to increase awareness of customer by the features of eco-friendly products will be increased, this promotes more profound perceptions and positive impact toward that kind of new technology. Also, restructure the consumer behaviour from conventional products to ecofriendly products. (Delafrooz, 2014, Sergio, et al., 2016).

Differently, Kinoti stated that not all organizations interest to apply green marketing because the company might face complications when implement green marketing due to lack of technology and extra cost of new innovative products (Kinoti, 2011).

The Green Marketing Strategy is based on the philosophy that useful for organized and integrated marketing through that aim to create the positive impact on the consumer preference. In order to motivate them towards the sustainable and ecological products. it works to provide the better-integrated marketing mix based on creativity which may increase the preservation of the natural environment. The application of green marketing concept is based on modifying the usage of natural resources and another type of raw materials. It is the most suitable for environment requirement and production activities modification to match with specific objective of green marketing (Ali, 2019).

It provides better opportunities for oil industry in terms of environmental accountability and evaluation. While green marketing considered the expected responsibilities of organizations so that it easily understands the behaviour of consumer, group of stakeholder and government towards green consumerism. Through strategy, lubricant industry concern about sustainable development to handle the intense pressure because of pollution, climate change.

Green Marketing is the best approach that mainly focused on environmental safety and performing different enterprises activities. It consists of production, modification in packaging and another type of green advertisement. In order to engage with the client practices and actions regarding environment friendly, the oil-based lubricants industry has attracted for effects of business operations in the environment, especially when the inadequate response of lubricant industry and increase the environment issues (Alamri, 2019). Therefore, it has raised the concern towards the commitment to sustainable development. 
In Saudi Arabia, many oil companies are under pressure and address their ecological footprint, which will try to mitigate sustainable development. The economic development within oil industry is vital for managing and controlling overall business opportunities.

In contrast, the difficulties for the company to apply green marketing strategies for costeffective factor because it is expensive and not simple to implement in the short run. Also, the environmental benefits are intangible, to end-user for instant customer could not feel or realize the emission reduction when using the green products instead of conventional oil in cars. (Ottman, 1997).

Jacobson (2019) argues that green marketing is a subject of promotion, which may refer to environmental condition that will implement positive activities in business for reducing environmental issues and problems.

This type of marketing emphasizes on ethics as per enterprise fundamentals. It is useful for the oil industry to expand their branches and fields through sustainable development.

The strategy consists of wide range of business operations which intends to satisfy client requirement and also reduce the adverse effects on the natural environment. Designing and implementing the green marketing strategy is not simple mission for the oil industry because it requires the proper and available resources, goals, and objectives. In order to increase the business profitability in marketplace, the organizations should have a clear vision so that easily margining the green activities.

Other energy sources like crude oil remain to have the essential role play in the lubricant industry. Nowadays, there are several divergent interests exists between the oil exploration, which may be growing the pressure also reduces the environmental impact causes though production of energy as well as consumption.

Utilizing of green marketing will increase the opportunities for the organization where the client should prefer the new green oil item and should be aware of the natural environment. In this way, Oil lubricant industry has changed their business activities while use green marketing strategies. (Jones \& Jain, 2019).

Many organizations realize that it has raised the opportunities in terms of competitive advantage. As in term of marketing, the Government wants to protect clients and secure their life. Therefore, it also made environmental legislation which intended to protect or secure consumer in different manner, to ensure that lubricant industry must control the hazardous waste and production of motor oil in limited manner. Otherwise, it will increase the environmental issues on regular basis. Considering the lubricants and oil offer scope due to green marketing in terms of improvement, switching to more energy-efficient option is highly beneficial for organizations who are focused on the environmental condition when various energy-efficient technologies combined with the operating practices which lead to increase high productivity of business in global marketplace.

The sustainability concept for business that can be determined as a strong collaboration between goals of gaining more profitability, through Green marketing strategies. Oil companies make their business more sustainable and invest in renewable energy sources. It is 
mainly generated from the other natural resources such as wind, tides, and sunlight. Also, organizations invest in the renewable source would not completely prove as profitable, but it also increases the demand in Saudi Arabia market. The concept of environmental responsibility that should be considered with legal obligation and economic condition for oil enterprise.

Kontic in his book greening the marketing Mix identify the difference between the conventional and green marketing mix as below Marketing Mix tools, usually in conventional marketing techniques. Product, Price, Place, Promotion. However, in green marketing, environmental concern is the main factor to be highlighted (Kontic, 2010).

The green product customer can be recognized as customer who supports eco-friendly trend products, similarly the end-user who has awareness with aspects of green products (Boztepe, 2012; Sergio, et al., 2016).

Most of customers are potential green consumer-oriented but with applying the proper method or technique to explain the advantage to be green, for example, any customer will choose the eco-friendly product compared with the conventional one if the price is equal or little higher (Awan, 2011).

On the same way the uncertainty avoidance index could affect the decision of buying for new technology or new technology. Uncertainty index measures the reaction for individuals in the country or society to the new ideas or future events. To what extent people will accept or resist future changes or new ideas. Cultural awareness plays a significant role in customer behaviour to try or applying a new concept. Plus, countries wealth and legal structure. Saudi Arabia considers one of high uncertainty avoidance index score. It means there is a challenge on how to convince the end-user to shift from conventional product to new green technology product. (Bart Frijnsa, 2013).

As per Islam and Huda (2020), when it comes to improve energy efficiency whereas oil industry has achieved success over past decade. The international energy agency has fallen the production of oil and gas in Saudi market due to the lack of processing efficiency. Even it increases the efficiency while intensive requires large amount of energy extraction, transportation, and processing. In this way, the opinion of expert has completely transformed towards sustainability to reduce emission of carbon dioxide. Sources and suppliers of renewable energy have continuously overgrown. The production of global biofuel production increased by $14 \%$ and constituting one of the most abundant sources of liquid products in the global world. It plays essential role within organization to produce low carbon fuels while contributing significantly most the sustainable development.

Oil and gas industry can transform the operation and function through increased energy efficiency and use of sustainable product, this strategy considers as an alternative method for increasing the profitability and productivity in global marketplace (Nunes, Causer, Ciolkosz, 2020).

The lubricant industry has recognized technology by running energy efficiency products and also beneficial for improving economic condition. Another way, it also emerging the oil 
industry to reduce power consumption while increasing the machine output in term of energy efficiency.

Moreover, lubricants industry utilised smart energy strategy to support reducing carbon emission, this strategy is the most suitable for organizations to handle the overall business operations and functions. The expert knows about energy improvement while increasing opportunities and reduce the rate of carbon emissions. In this way, it becomes easier to measure the energy efficient such as selecting appropriate right lubrication items that directly give positive impact on environmental subjects. Thus, it allows for the organization to maintain the safety and ecological condition. In order to improve the work environment and handle the business challenges professional manner (Vogl, Weiss, Helu, 2019).

From previous studies there is a gap at the subject of relation between applying CSR and improving the business performance in particular segment or industry like oil \& gas, that is why further studies are highly recommended to bridge this gap between the recent researches and the current market situations in oil \& gas industry in the Middle East, specifically in Saudi Arabia. Introducing the concept of new technology for green products lubricants sector and evaluate the consumer perceptual toward this ecological vision.

\subsection{Role of CSR in Organization Performance}

CSR has become critical issues for today's organizations, it mainly refers to continue the commitment of enterprise towards ethical and moral value in terms of economic development while continuously improving overall quality of the organization. The traditional enterprise approaches are primarily emphasizing within the economic aspects of organization's activities. It was found out that increases the social as well as environmental issues. When applying corporate social responsibility within lubricants industry, which will bring more advantages and showing the goodwill to improve the reputation of business in global marketplace. In this way, it is increasing employee's engagement and customers satisfaction. Besides, it is expanding the business through consumer baseline while applying the organizational policies related to the social and environmental subjects (Zhang \& Lim, 2019).

In the Saudi Arabia market, many organizations are emphasized with the structure of corporate strategic marketing based on different factors such as corporate resources, corporate culture. In contrast, Friedman defined the main goal for business to maximize the company benefits. Exploit the resources and involve in planes designed to increase income for corporation and invest more assets to expand the organization activities, in free and fair competition without fraud and dishonesty, this theory argued the CSR concept by considering the social and environmental factors. (Friedman, 2007). Nevertheless, the benefits of CSR are creating engagement program and also including the profitability while enhancing the reputation, brand recognition, boosting employee engagement and risk management. CSR policies always encouraging the staff member for developing social as well as sustainable change within organization. It is totally based on the building the functioning corporation that possesses a substantial value and helps to manage risks and become a more competitive brand. Moreover, environmental disaster has become significant issues that would be exposed 
by different marketing. Nowadays, it is possible to aware of the corporate scale due to lack of trust. Therefore, it has chances for increasing the social responsibility issues within the lubricants industry. In order to make effective CSR policies which help for controlling lack of trust, which may increase pressure on organization. Environment issues pushed into the limelight where corporation is now looking for change sustainable. There are two crucial elements which play a vital role in corporate social responsibilities such as accountability and transparency (Trivellas, 2019).

As per Zhu, Zou, and Zhang (2019), CSR is simply the best way to hide the mask of responsibility and obligation. It is based on the situation where many organizations integrate with environmental concern in their daily business enterprise and their significant interaction with other stakeholders. It is not only making money for multiple shareholders, but it also improves the overall condition of business in global market. In most cases, decisions should be made on behalf of financial reasons and also consider the environmental impact, investment, enterprise ethics and human right. In lubricants industry, CSR is all about the enterprise that is accountable for activities and practices that effects on the overall social community and environment.

An effective CSR policy are more robust for increasing profit rate whereas they invest in the growth of business development and sustainable practices. It is the key success of organization to improve the employee working capabilities where business driving CSR initiatives while building secure communication between staff members, in order to motivate every employee and responsible for maintaining sustainable development. On the other hand, CSR policies will help to transform entire business into growth and development. In lubricant sector, rigorous CSR policies become key component to improve the overall business performance in terms of sustainable development. It helps in maintaining position in terms of ethical and moral values. These types of CSR server to create sustained trust among organization and consumer. Thus, it is easily attracting the new business partner and reinforce existing relationships while increasing market share. (Frynas \& Yamahaki, 2019).

Newman, Rand, \& Trifkovic (2020) argued that CSR becomes far from the solution to different social problem due to fewer resources, but in most of cases, CSR consists of essential guideline to follow as future strategies. The lubricant organizations are preventing their limited resource from coping with various social obligation where government has more responsibilities to handle the situation. CSR capture sustainable development and attention towards the companies that mainly focused on environmental issues. In this way, lubricants sector contribution towards sustainable development to adopt stakeholder theory and improve business management.

Stakeholder approaches may represent inconsistencies through the idea of sustainable because it does not entirely imply that all stakeholder, it could be beneficial from corporate social policies which are putting more efforts to treat equally, and ensures that organization will create more value through stakeholders (Walker, Zhang, Ni, 2019). The organizations are adopting CSR policies and governance as control entire system of integration in terms of social as well as environmental, for increasing business performance. Management trends are impacting on the business strategies, which mainly adopt themselves for changing the 
environments (Sergio, et al., 2016). It may include enterprise models and stakeholder pressure for corporate social responsibilities compliance. Therefore, many organizations can take advantage through CSR while achieving the significant goals and objective of a business. Recently, stakeholder engaged with CSR policies and involves different process such as identifying environmental issues and stakeholder management. In this way, it can be determined that CSR is a vital concept which always helping for corporate identity, communication also building a productive relationship with another. Also create the longterm growth, it always has initiatives towards CSR policies which will promote the lubricant sector positively targeting to the existing consumer. In this way, it will be creating the workforce and generate more profit while repeat enterprise to enhance productivity as well as profitability in global marketplace (Srivastava \& Shree, 2019).

Furthermore, CSR considered an essential part of strategic planning for lubricants industry that strives to be successful and wants to improve the business reputation. Especially, those companies want to be explored their business in a competitive environment. CSR can be integrated with business policies within organization and supplement the significant goals. Thus, it becomes a significant part of business capitals that will monitor targets and incentives. The data gathering process defined as a method used to collect various types of research data, this research survey based on primary data. The web-based technique is a time and cost-effective process. The researchers collects data directly from key sources through a questionnaire to maintain the relevance and effectiveness of the data. A web-based survey is a source to collects the primary data directly from respondents. For this survey, Monkey Survey tool used to start the questionnaire. Through this approach, it is possible to target a large number of samples.

The policies are recognized that CSR is not compliance and commitment for supporting which improve the lives of people under the circumstances within organization. On the other hand, it also promotes equality to implement an innovative idea which helps to improving the overall business capabilities and abilities. (Crane, Matten, Spence, 2019).

\section{Methodology}

In this paper, the quantitative data type used to meet the objectives of the study. The design of research is related to the overall methodology that the researchers decided to apply, in order to ensure that the research problem is adequately investigated. The researcher followed the descriptive-correlation design with a survey that ensures no manipulation of any study variables and the data collected at the same time. The method for analysing relations between the variables is often referred to as the term correlation in order to prove the research objectives. The respondents were selected through accessibility-snowball sampling technique. To investigate the research objectives, the researcher conducted two surveys by answering research questions $(n=163)$. First survey $(N 1$ Survey, $n=126)$ concerns lubricant green oil endusers, such as motorists and vehicle owners. The second survey (N2 Survey, $n=37$ ) targets experts in the oil \& gas industry. The questionnaire reliability used Cronbach's Alpha values 0.70 for variable, and the questionnaire error factor $\sigma=5 \%$ which indicates that it is 
appropriate for this study. Data for this study were collected using a questionnaires web-based links on survey monkey platform at peak of the pandemic.

\section{Results and Discussion}

\subsection{Corporate social responsibility policies improve organization performance as perceived by the respondents}

The Table 1 below shows the experts' with different years in the field and their point of view regarding CSR policies can bridge the gap between gaining more benefits for the organization and business sustainability for ecological responsibility. Across different expert levels and varied years of experience (high, medium, and low) in the oil \& gas field, $100 \%$ of them are agreed that CSR policies can bridge the gap between gaining more benefits for the organization and business sustainability for ecological responsibility.

Table 1: The correlation between respondents with different experiences and their opinion about CSR policies and approaches

\begin{tabular}{|c|c|c|c|c|c|c|c|c|c|c|}
\hline & \multicolumn{2}{|c|}{ Less than 5 years } & \multicolumn{2}{|c|}{5 to 10 years } & \multicolumn{2}{|c|}{11 to 15 years } & 16 to 20 years & \multicolumn{3}{|c|}{ Total } \\
\cline { 2 - 12 } & Count & PCT & Count & PCT & Count & PCT & Count & PCT & Count & PCT \\
\hline Yes & 7 & $100.0 \%$ & 10 & $100.0 \%$ & 13 & $100.0 \%$ & 7 & $100.0 \%$ & 37 & $100.0 \%$ \\
\hline No & 0 & $0.0 \%$ & 0 & $0.0 \%$ & 0 & $0.0 \%$ & 0 & $0.0 \%$ & 0 & $0.0 \%$ \\
\hline Total & 7 & $100.0 \%$ & 10 & $100.0 \%$ & 13 & $100.0 \%$ & 7 & $100.0 \%$ & 37 & $100.0 \%$ \\
\hline
\end{tabular}

The consensus from all experts' respondents showing the positive attitude and give great expectations for CSR policies and how it will maintain the organization improvement a side with gaining profits can be sen in Table 1. This figure recorded the opinions of industry expert according to the concept of the organization with more social responsibility and how it will bring more investment and improve the organization's financial performance. The finding for survey complied with the intellectual and recent research conducted by Zhang, Lim (2019), how expanding the business through consumer baseline while applying the organizational policies related to the social and environmental subjects. In addition, the results found supportive for the recent research finding of Srivastava \& Shree by emphasised the CSR generate more profit while arrange enterprise to enhance productivity as well as profitability in global marketplace (Srivastava \& Shree, 2019). 
5.2 The feedback of lubricants industry experts in terms of gender and end-user in Saudi Arabia market toward the green products use

Table 2: End user respondents' feedback toward green oil technology as new concept.

\begin{tabular}{|l|l|l|}
\hline Option & Respondent & Percentage \\
\hline Extremely innovative & 28 & $22.40 \%$ \\
\hline Very innovative & 64 & $51.20 \%$ \\
\hline Somewhat innovative & 31 & $24.80 \%$ \\
\hline Not so innovative & 2 & $1.60 \%$ \\
\hline Not at all innovative & 0 & $0.00 \%$ \\
\hline Total & 125 & \\
\hline
\end{tabular}

As elucidated in Table 2, it observed that more than $70 \%$ are between extraordinarily innovative and very innovative. The $24.80 \%$ respondents are neutral regarding this concept.

From the data, it points on the innovative concept of green motor oil with eco-friendly advantage. This type of creative idea helps for inspiring many customers to purchase the green motor oil. Therefore, there is increasing the popularity of a new concept in Saudi Arabia market while gaining more profit margin regularly. The feedback for the concept of using green technology products as a part of green marketing strategies in lubricants KSA market noticed very positive and supportive attitude. This result has been supported by Sergio, et al., 2016 that Green Marketing Strategies and innovation in support of eco-environment in promoting organizational profit.

\subsection{The Green Marketing Strategies that Contributes to Organizational Growth}

Table 1. How the CSR through Green Marketing can increase the profitability in KSA

\begin{tabular}{|c|c|c|c|c|c|c|c|c|c|c|}
\hline & \multicolumn{2}{|c|}{$\begin{array}{c}\text { Less than } 5 \\
\text { years }\end{array}$} & \multicolumn{2}{|c|}{5 to 10 years } & \multicolumn{2}{c|}{11 to 15 years } & \multicolumn{2}{c|}{16 to 20 years } & \multicolumn{2}{c|}{ Total } \\
\cline { 2 - 12 } & $\begin{array}{c}\text { Coun } \\
\mathrm{t}\end{array}$ & $\mathrm{PCT}$ & $\begin{array}{c}\text { Coun } \\
\mathrm{t}\end{array}$ & $\mathrm{PCT}$ & $\begin{array}{c}\text { Coun } \\
\mathrm{t}\end{array}$ & $\mathrm{PCT}$ & $\begin{array}{c}\text { Coun } \\
\mathrm{t}\end{array}$ & $\mathrm{PCT}$ & $\begin{array}{c}\text { Coun } \\
\mathrm{t}\end{array}$ & $\mathrm{PCT}$ \\
\hline $\begin{array}{c}\text { Strongly } \\
\text { agree }\end{array}$ & 1 & $14.3 \%$ & 3 & $30.0 \%$ & 1 & $7.7 \%$ & 0 & $0.0 \%$ & 5 & $13.5 \%$ \\
\hline Agree & 6 & $85.7 \%$ & 6 & $60.0 \%$ & 9 & $69.2 \%$ & 6 & $85.7 \%$ & 27 & $73.0 \%$ \\
\hline $\begin{array}{c}\text { Neither } \\
\text { agree } \\
\text { nor } \\
\text { disagree }\end{array}$ & 0 & $0.0 \%$ & 1 & $10.0 \%$ & 2 & $15.4 \%$ & 1 & $14.3 \%$ & 4 & $10.8 \%$ \\
\hline $\begin{array}{c}\text { Disagre } \\
\mathrm{e}\end{array}$ & 0 & $0.0 \%$ & 0 & $0.0 \%$ & 1 & $7.7 \%$ & 0 & $0.0 \%$ & 1 & $2.7 \%$ \\
\hline $\begin{array}{c}\text { Strongly } \\
\text { disagree }\end{array}$ & 0 & $0.0 \%$ & 0 & $0.0 \%$ & 0 & $0.0 \%$ & 0 & $0.0 \%$ & 0 & $0.0 \%$ \\
\hline Total & 7 & $\begin{array}{c}100.0 \\
\%\end{array}$ & 10 & $\begin{array}{c}100.0 \\
\%\end{array}$ & 13 & $\begin{array}{c}100.0 \\
\%\end{array}$ & 7 & $\begin{array}{c}100.0 \\
\%\end{array}$ & 37 & $\begin{array}{c}100.0 \\
\%\end{array}$ \\
\hline
\end{tabular}


The table illustrates that the senior managers (with experience above 16 years in the field) thought it might initially cost finance in business and will certainly lead to enhanced performance branding and public relations, increased profitability, with $85.7 \%$ of respondents agreeing. The $15 \%$ neutral and $2.70 \%$ disagree with the CSR stratégy to contribute to organizational growth. Both of industry experts and end-users agreed with needs to adopt the green motor oil technology, which helps in increasing the customer-base of company in the Saudi marketplace. Furthermore, most of customers show interest in buying the green motor oil product if it is available in market with consideration of price and financial point. The product should be at the same price or slightly higher compared with other conventional products., the innovative concept of green motor oil with eco-friendly advantage. This type of innovative idea helps for inspiring many customers to purchase green motor oil. Therefore, it is increasing the popularity of a new concept in Saudi Arabia market while gaining more profit margin on regular basis. Additionally, investing in environmental, ethical practices by using vegetable oil and eco-friendly additives in motor oil formula, and saving fuel, improve engine performance, consider a privilege, and outweigh the rivalry for the new green oil motor oil. It adds excellent impression for both customers and industry expert. This procedure undoubtedly leads to enhanced performance branding plus increase profitability. The studies of Crane, et al., 2019 and Sergio, et al., 2016 support the major findings of this study.

\section{Conclusion}

The results spotted the positive attitude and encourage consumer behaviour for the new motor oil product with extraordinary benefits such as extra mileage performance, saving petrol and ecological considerations. Based on data collected from surveys it becomes essential to start a marketing campaign to introduce more awareness for customers, therefore the crucial role of green marketing can be identified. This research highlighted the critical role of Green Marketing in oil \& gas field particularly and business practising generally. New innovative science or chemical projects with excellent product specifications should not be enough to increase the market share or approach more profits for the company, but it is mix between two types of science: marketing and chemistry science. The researcher examined that in interactions of respondents and how the environmental and ethical practising considered a side commercial and business benefits. The CSR policies can play a crucial role in organisation's growth. The Green Marketing Strategy is considered a vital tool in modern corporate planning and strategy. The findings proved that adopting a CSR strategy increases the employee engagement and commitment. Moreover, CSR improves the image of the organisation, enhances the confidence, and adds a positive impact for the staff, suppliers, customers, and shareholders. Also, the company can gain more profits by promoting new technology in oil \& gas field. Therefore, the business can attract more investors and funding by investing in environmental projects. 


\section{Acknowledgment}

The researchers sincerely thank the Human Resources head of the involved lubricant sectorbased companies for allowing the researchers to interact with their employees who serve as the research community.

\section{References}

Ahmed, J., Sultana, H. A, \& Khan, A. (2018). Saudi Aramco: A Blend between Profit and Politics. FIIB Business Review, 7(2), pp. 88-99.

Alamri, Y. (2019). Three Essays on Saudi Arabia Agricultural Markets, s.1.: s.n.

Ali, S. (2019). Evaluation of the effectiveness of green practices in manufacturing sector using CHAID analysis. Journal of Remanufacturing, 9(1), pp. 3-27.

Awan, U. (2011). Green Consumer Behavior: Empirical Study of Swedish Consumer Behavior, Vasteras: s.n.

Bart Frijnsa, A. G. T. L. A. A. T.-R. (2013). Uncertainty avoidance, risk tolerance and corporate takeover decisions. Journal of Banking \& Finance, 37(7), pp. 245-247.

Boztepe, A. (2012). Green Marketing and Its Impact on Consumer Buying Behaviour. European Journal of Economic and Political Studies, Volume 1, pp. 5-21.

Delafrooz, T. A. N. (2012). Effect of green marketing on consumer purchasing behavior, s.1.: s.n.

Friedman, M. (2007). the social responsibility of business to increase profitability. In: Corporate Ethics and Corporate Governance. s.1.:s.n., pp. 173-178.

Frynas, J. A. Y. C. (2019). Corporate Social Responsibility: An Outline of Key Concepts, Trends, and Theories. In Practicing CSR in the Middle East. In: Cham: Palgrave Macmillan, pp. 11-37.

Islam, M. \& Huda, M. (2020). Reshaping WEEE management in Australia: An investigation on the untapped WEEE products. Journal of Cleaner Production, Volume 250, pp. 9496.

Jacobson, M. (2019). Marketing madness: A survival guide for a consumer society. s.l. Routledge.

Jones, E. \& Jain, S. (2019). Evaluating the Impact of Sustainability and Pipeline Quality on the Global Crude Oil Supply Chain. Supply Chain Engineering and Logistics Handbook: Inventory and Production Control, p. 49.

Kinoti, M. W. (2011). Green marketing intervention strategies and sustainable development: A conceptual paper. International Journal of Business and Social Science, pp. 2-23. 
Kontic, I. \&. B. J. (2010). Greening the marketing mix - A case study of the Rockwool Group, Jönköping: s.n.

Krane, J. (2018). Climate Strategy for Producer Countries: The Case of Saudi Arabia, s.l.: s.n.

Newman, C., Rand, J. T. F. \& Trifkovic, N. (2020). Corporate social responsibility in a competitive business environment. The Journal of Development Studies, pp. 1-18.

Nunes, L., Causer, T. \& Ciolkosz, D. (2020). Biomass for energy: A review on supply chain management models. Renewable and Sustainable Energy Reviews., Volume 120.

Ottman, J. A. (1997). Green marketing, opportunity for innovation. In: s.l.:NTC publishing, pp. $45-126$.

Rajeshkumar, L. (2012). An overview of green marketing. Naamex International Journal of Management Research, 2(1), pp. 128-136.

Sergio, R. P., Refaat, M., \& De La Cruz, K. M. E. (2016). Increasing Level of Stakeholders' Involvement Drives the Organization's Corporate Responsibility as Profitable Investment: A Research Review. IAMURE International Journal of Business and Management, 13(1), 1-1.

Srivastava, A. \& Shree, S. (2019). Examining the effect of employee green involvement on perception of corporate social responsibility: Moderating role of green training. Management of Environmental Quality, 30(1), pp. 197-210.

Suki, N. M. (2013). Green Awareness effects on consumer's purchasing decision. Some insights from Malaysia. Green awareness effect, Volume 9, pp. 50-63.

Trivellas, P. (2019). Corporate social responsibility (CSR) and its internal consequences on job performance. International Journal of Quality and Service Sciences.

Vogl, G., Weiss, B. \& Helu, M. (2019). A review of diagnostic and prognostic capabilities and best practices for manufacturing. Journal of Intelligent Manufacturing, 30(1), pp. 79-95.

Walker, K., Zang, Z., \& Ni, N. (2019). corporate social irresponsibility and firm performance in coordinated market economies and Liberal market economies. British Journal of Management, 30(1), p. 1.

Yazdanifard, R. M. I. E. (2011). The impact of green marketing on customer satisfaction and environmental safety. International Conference on Computer Communication and Management, Volume 5, pp. 637-641.

Zhang, Q. O. B. \& Lim. B. (2019). Drivers, motivations, and barriers to the implementation of corporate social responsibility practices by construction enterprises. Journal of cleaner production, Volume 210, pp. 563-584.

Zhu, Q., Zou. F., \& Zhang, P. (2019). The role of innovation for performance improvement through corporate social responsibility practices among small and medium- sized 
suppliers in China. Corporate Social Responsibility and Environmental Management, 26(2), pp. 341-350. 